\title{
PAISAJES DE LOS CONDENADOS \\ EL ESCENARIO NATURAL DE LA CASA VERDE
}

MICHAEL MOODY

Por

University of Idaho

El escenario es uno de los aspect os más expresivos de La casa verde; abarca dimensiones que van más allá de las de tiempo y espacio. En esta novela Vargas Llosa pone al manifiesto con extraordinaria habilidad artística un constante esfuerzo creador a fin de revelar la realidad en una multiplicidad de niveles y exhibirla en maneras nada convencionales. Esta discusión empieza con una consideración del escenario que parte de la premisa de que por debajo de la fuerza expresiva cobrada por éste a lo largo de la novela yace una pertinencia temática constante. Se hará un esfuerzo para mostrar que los rasgos distintivos del medio ambiente sirven para definir no sólo la situación vital de los personajes sino también los valores literarios que dan cuerpo a la visión de la realidad del autor.

Un escenario doble proporciona el fondo ambiental para la acción que se desarrolla en La casa verde. Hacia el norte está Piura, una ciudad de provincia situada en el desierto árido de la costa. Como otros centros urbanos, sufre los problemas sociales de un crecimiento económico desigual y desordenado. Por un períod o de unos cuarenta años, ocurren severas dislocaciones en la vida, las tradiciones y la personalidad colectiva de sus habitantes. Allá lejos, hacia el este, en la inmensidad verde y primitiva del Amazonas peruano, hay un pequeño establecimiento de comercio, Santa María de Nieva. Aquí, un grupo de monjas españolas continúa con la lucha empezada hace siglos por llevar las enseñanzas de su iglesia y de su civilización a los indios que viven en esa región.

Cuando le han pedido a Vargas Llosa que comentara su propia novela, él se ha referido a los escenarios de La casa verde como "lugares totalmente antagónicos":1 son tan distintos entre sí que él los llama "dos mundos".2

I Elena Poniatowska, "Al fin un escritor que le apasiona escribir, no lo que se diga de sus libros: Mario Vargas Llosa", La Cultura en México, No. 117, suplemento de Siempre!, 7 de julio de 1965, p. 2.

2 Mary de González León, "Conversación con Vargas Llosa", en el suplemento de Imagen [Caracas], No. 6, 1-15 de agosto de 1967, p. 9. 
Seguramente, éstas son descripciones fidedignas de la realidad física y social de las dos comunidades. La yuxtaposición misma de Piura y Santa María de Nieva implica una indicación de la inmensidad y de la diversidad física del Perú. Además, estos lugares representan manifestaciones de procesos históricos muy diferentes, y su coexistencia en el tiempo es en sí un comentario sobre las intensas contradicciones a parentes en el desarrollo cultural del Perú. Su contigüidad en la novela implica necesariamente una interacción entre niveles diferentes de realidad física y social.

Hay que decir, sin embargo, y debido precisamente a que es tan obvia la dualidad inherente en los escenarios de la novela, que resulta ineludible el hacer hincapié en la función literaria de éstos. Como componentes de un esquema más amplio, los escenarios están incorporados dentro de un complejo narrativo que encierra una visión unificadora. Hay una multiplicidad de relaciones en los niveles de tema y estilo que crean fuertes lazos entre los "dos mundos" de modo que éstos acaban adquiriendo ciertas características mutuas, y muchas de las aparentes desemejanzas entre ellos pasan a un segundo plano. Visto como una totalidad y en relación con otros elementos literarios, el escenario añade un importante factor de cohesión y unidad a la estructura fragmentada de la novela.

Una metáfora dominante en la novela tiene que ver con la idea del entrampamiento. Como motivo, este concepto opera en todos los niveles que figuran en la estructuración que la novela da a la realidad. En el escenario natural, produce la casi palpable sensación de aislamiento que caracteriza ambas comunidades.

Con el uso de frecuentes referencias a diferentes tipos de muros y barreras, la selección de imágenes intensifica el establecido clima sicológico de soledad y enajenamiento del mundo exterior. Es significativo el que términos metafóricos de esta índole intensifiquen las primeras impresiones producidas en el lector por ambas regiones. Aprovechando un vocabulario que por regla general sólo se aplica a los seres vivos, el autor educe una impresión de la naturaleza como una presencia orgánica, de animal. ${ }^{3}$ Tanto el desierto como la selva están descritos repetidamente en términos que sugieren formas y funciones animales. Otro tipo de imagen vivificante comunica una dimensión aún más alarmante. En tales formas como "troncos leprosos" y "árboles decapitados" (p. 26) hay elementos generalizados de dolor y de enfermedad aplicados a objetos inanimados, lo que sugiere el caos de un mundo natural cuyas formas están corrompidas y desfiguradas.

\footnotetext{
${ }^{3}$ El término "naturaleza" es utilizado aquí para indicar todo lo que hay en el mundo material con excepción del hombre y sus creaciones.

${ }^{4}$ Mario Vargas Llosa, La casa verde (Barcelona: Editorial Seix Barral, S.A., 1966), p. 319. Todas las referencias que siguen provienen de esta edición.
} 
El medio ambiente físico, sin embargo, no es tan sólo pasivo en su relación con el hombre. El lenguaje metafórico atribuye valores subjetivos a la naturaleza que revelan un comportamiento amenazadoramente hostil y agresivo. Por medio de un lenguaje que embrutece la naturaleza, las fuerzas que rodean al hombre cobran una potencia irracional para ser violentos contra él.

El motivo de la agresión contra el hombre y sus obras es una rica fuente de imágenes en la novela. Sin embargo, al proyectarse las primeras impresiones de Santa María de Nieva y Piura, se utilizan términos equivalentes. La descripción de la Misión incluye estos renglones:

Desde la Misión un sendero escarpado desciende hasta la Plaza. Y detrás de la Misión un muro terroso resiste el empuje del bosque, la furiosa acometida vegetal. (p. 26)

Aunque los términos usados son otros, la naturaleza pone un sitio parecido a Piura:

La gente se recluye en el hogar a la caída de la tarde para librarse del viento sofocante y de la acometida de la arena que lastima la piel como una punzada de agujas y la enrojece... (p. 32)

La naturaleza tienta continuamente las defensas del hombre, buscando cualquier zona de debilidad donde pueda vencer resistencias y establecer su propio dominio. La acción más conspicua iniciada por la naturaleza es expresada por verbos que comunican una agresión activa y violenta. Cuando los piuranos se enteran del proyecto de don Anselmo de construirse una casa en las afuerzas de la ciudad, su reacción revela un conocimiento de la honda hostilidad del desierto. La construcción misma de la casa es representada como un conflicto abierto con el desierto; una contienda primordial con un adversario capaz de una confrontación bien dirigida y sostenida.

Tales descripciones realzan sustancialmente el ambiente emocional de la novela e infunden un tono portentoso, amenazador, en la visión de la naturaleza. La ferocidad de la agresión de la naturaleza es intensificada aun más por el fuerte elemento de crueldad que da origen a gran parte del lenguaje metafórico de la novela. Una dimensión de tortura y mutilación físicas desempeña un papel en el proceso de destrucción. El uso casi obsesivo de verbos como "devorar" y "tragar" para describir procesos naturales subraya continuamente la intensa voluntariedad de los antagonistas alineados en contra del hombre. A la larga, la utilización constante de estos términos produce una interpretación de la naturaleza como despiadado y maligno atormentador.

En ninguna parte, quizá, llega a ser más simbólicamente sugestivo el castigo del hombre por la naturaleza que en su materialización en varias clases de símbolos de lluvia. Dentro de la novela, ninguna otra actividad de la 
naturaleza atiende tan constantemente la descripción de las acciones de los hombres. Cada noche sobre Piura baja del desierto un viento armado de arena. Cuando llega a la ciudad, "se divisa entre el cielo y la tierra como una deslumbrante coraza" y después "vacía sus entrañas" (p. 31). Desde el crepúsculo hasta el alba cae despiadadamente la arena. Este fenómeno raro es la caracterísitca física más distintiva de Piura. Los ciudadanos se acostumbraron hace mucho tiempo a ordenar su vida según la invasión nocturna del desierto. Al anochecer, la gente se recluye en el hogar para librarse de la hiriente acometida de la arena que cae; por las calles reverberan fantasmales configuraciones de sonido. Los que se atreven a salir reciben en los ojos, en las manos y en la cara la punzada de minúsculas partículas puntiagudas. Por la noche, y todas las noches, el asedio sigue; no se termina nunca.

Un paralelo significativo ocurre en el escenario de la selva donde no es menos penetrante la lluvia casi incesante. Las imágenes utilizadas para describirla comunican a veces una cualidad dura, pedregosa ("los goterones caen como pedradas" [p.35]) o indican una negrura y un calor poco comunes. También tiene la lluvia de la selva equivalentes simbólicos que asumen formas más amenazadoras. Acampados en plena selva, el Sargento se queja a sus hombres: "Hicieron la carpa justito debajo del árbol... Nos van a llover arañas toda la noche" (p. 124). Significativamente, el mismo particular es reproducido por un símil donde el escenario es Piura: "Llovía suave, los granitos de arena no se veían, se los sentía en la cara y en los brazos como patitas de araña"(p. 161). En Iquitos, el fenómeno de la lluvia adquiere aún otra forma: "una sirena perfora el aire, el humo negro de la chimenea se espesa y llueven partículas de carbón sobre la gente"(p. 399). Arena, lluvia, arañas y partículas de carbón caen sobre la cabeza de los hombres, castigándolos por algún crimen desconocido; un pecado olvidado: Su situación y las varias formas de su castigo asumen significad os fuertemente arquetípicos. El mundo físico encierra una visión turbulenta de un infierno donde el hombre es condenado a sufrir y a desesperar.

Como otros elementos de la naturaleza, el sol adquiere vida y conciencia a base de metáforas que sitúan su ser y función en una esfera de animalidad. Otras cualidades atribuidas al sol son perfectamente compatibles con el clima de violencia y brutalidad que la naturaleza impone en el medio ambiente humano. El uso de verbos como "disparar" y "alancear" para describir el movimiento de los rayos del sol evoca impresiones de ardientes proyectiles lanzados contra el hombre en una especie de bombardeo infernal.

Dentro del motivo de la agresión, resulta lógico y es válido en términos literarios el uso de un mayor atrevimiento en la selección de imágenes. El motivo permite, además, que otros detalles de mínima importancia cobren un sentido más amplio cuando se ven en relación con la totalidad del cuadro. Tal 
es el caso con un número limitado de símiles que comparan el sol con otros agentes de destrucción ("el sol hendía como una cuchilla" [p. 359]) y relacionan insigificantes actos humanos con contex tos conflictivos ("Manuel Águila utiliza el abanico como un escudo contra el sol, pero a un así lagrimea" [p. 197]).

Como símbolo literario, el sol llega al cenit de la expresividad en la escena que relata la tortura y ejecución en la horca de Jum en la plaza de Santa María de Nieva. Ubicada en el epílogo, la escena da la impresión de un clímax fuerte aunque el lector sabe, a base de cambios temporales anteriores, que el suceso no señala la muerte física de Jum. Es, más bien, en el nivel de lo simbólico que alcanza esta escena su valor más signficativo.

Debido a que se ha atrevido, con la organización de una humilde cooperativa, a declararse en contra de las normas existentes de explotación económica, Jum sufre un martirio cruel en una forma eminentemente sugestiva de la crucifixión de Cristo. Con las manos atadas sobre la cabeza y la piel de las axilas mutilada por huevos calientes, Jum cuelga suspendido en el vacío, agonizando hora tras hora bajo un sol abrasador, mientras que desde abajo lo atormentan con sus insultos los soldados y demás observadores curiosos. Presenta la escena Julio Reátegui, gobernador de Santa María de Nieva y autor del castigo de Jum. Como versión moderna de Poncio Pilato, Reátegui entiende la realidad tan mal y de una manera tan grotesca que es capaz de negar su culpa personal delante de la Superiora y lavarse las manos del asunto. Ya que Reátegui impone castigos a base de informes erróneos, y hasta puede decirse que lo hace sin malicia, Jum se convierte en víctima de una increíble perversión de la verdad. Es un contexto absurdo para el drama de su expiación.

Al salir de la Misión, Reátegui decide tomar un trago con unos amigos antes de salir del pueblo. Baja la empinada pendiente que lleva a la plaza y se detiene brevemente para observar el cuerpo suspendido. La intensidad de la escena es muy fuerte y ningún otro elemento determina su composición mejor que la serie consecutiva de alusiones al sol:

El sol es crudo, vertical, de un amarillo casi blanco. Reátegui da unos pasos hacia la Gobernación, pero al pasar ante las capironas se detiene y vuelve a mirar. Sus dos manos prolongan la visera del casco y aun así los rayos agresivos hincan sus ojos... La posición en que se halla [ Jum] ha sumido su estómago y alargado su cuerpo, se diría un hombre delgad o y alto, no el pagano fortachón y ventrudo que es. Algo extraño transpira de él, así como está, quieto y aéreo, convertido por el sol en una esbelta forma incandescente. (p. 382)

En el blanco relumbrón del sol de mediodía se pierde la identidad de Jum en un flujo de luz torrencial. Su ser brilla en el calor de un fuego consumidor y 
después se disuleve o desaparece en materia amorfa. La experiencia sufrida por Jum en la plaza de Santa María de Nieva es una muerte simbólica que significa el final de su existencia previa. A partir de este momento, dimite como jefe de la comunidad india de Urakusa y se dedica a una vida de expiación que él mismo se impone. Jum sufre una pesada carga de culpabilidad con la peculiar y algo patética creencia de que él es responsable por las atrocidades cometidas contra su raza por los hombres de Reátegui. Su futuro es un esfuerzo inútil por recuperar las pérdidas del pasado.

Como fuente principal de la luz, el sol desempeña un importante papel de apoyo en la activación de la visión animística de la naturaleza presentada en esta novela. Una continua interacción de luces y sombras explica en parte el que se vean los fenómenos naturales como fluctuantes entre estados contrarios de movimiento e inmovilidad. Por debajo de toda la naturaleza se extiende una tensión dinámica, creando un plano inestable de agitación y cambio constantes.

La vitalidad del mundo físico se revela en dos tipos de movimiento: en un nivel, la naturaleza avanza inexorablemente hacia la muerte y la desintegración, mientras que en otro, una vibración y un flujo potenciales caracterizan sus elementos. La superficie del desierto de Piura, por ejemplo, cambia continuamente. Dunas movedizas destruyen a diario viejas formaciones y crean otras nuevas. A cierta distancia, la arena, el calor y la desolación borran las líneas de la ciudad y producen la impresión de una ilusión óptica gris y oscilante. En Santa María de Nieva las circundantes "dunas boscosas"(p. 195) crean parejas formas de cambiantes configuraciones y contornos. En ambas regiones, la inestabilidad es siempre la misma. Mientras viajan por un río de la selva, Aquilino dirige este comentario a Fushía:

... los que hacen mapas no saben que la Amazonía es como mujer caliente, no se está quieta. Aquí todo se mueve, los ríos, los animales, los árboles. Vaya tierra loca la que nos ha tocado, Fushía. (p. 51)

En este endeble e inquieto ambiente natural, la refracción de la luz produce efectos extraños, a veces alucinatorios. Las referencias a las condiciones de la luz-una parte integral de casi todas las descripciones de escenario-evocan continuamente una imagen de revolante y trémula energía. Una vista de la Misión contiene una impresión típica: "bajo el cielo limpio la Misión resplandecía ya entre los árboles, sus calaminas y sus muros reverberaban mansamente en la luz clara de la madrugada" (p. 355).

Por la tarde y por la noche, trémulos rayos de luz pueblan el ambiente con sombras caprichosas y furtivas que prestan misterio y aspectos fantasmagóricos al escenario. A la hora del crepúsculo en Santa María de Nieva, tanto la gente como los objetos son definidos por la peculiar intranquilidad del ambiente aéreo: 
La bruma lo cubría todo ahora $\mathrm{y}$, entre sus vuelos y danzas ambiguas, las cabañas y los árboles flotaban suavemente, se oscurecían y aclaraban, y había siluetas huidizas circulando por la Plaza. (p. 211)

Efectos ópticos de esta índole envuelven claramente una percepción y una complicidad subjetivas o por parte del narrador o por algún personaje que ha participado en la escena. Sin embargo, mientras siga siendo suficientemente neutra la tonalidad emocional producida por estos efectos, el lector seguirá asociándolos con la descripción objetiva de la realidad física. Pero cuando estas descripciones realzan enérgicamente el ambiente emocional de una escena particular, su impacto emotivo es sentido con toda su fuerza y se descubren nuevos niveles de significación. Un ejemplo de la manera en que unos rasgos pertenecientes a la naturaleza son capaces de infiltrar el mundo subjetivo de los personajes y formar un clima emocional, puede sacarse del episodio en que el Sargento viola a Bonifacia. La escena empieza con una serie de imágenes descriptivas que tienen en común referencias directas o indirectas a un ritmo oscilante:

Las piernas desnudas del Sargento colgaban de la escalerilla del puesto y alrededor todo ondulaba. Las colinas boscosas, las capironas de la Plaza de Santa María de Nieva, hasta las cabañas se balanceaban como tumbos al paso del viento tibio y silbante. (p. 171)

Estas primeras líneas establecen una perspectiva en la que los objetos y los hombres, ambos, participan en el flujo y reflujo de la naturaleza. La descripción que sigue acumula aun más imágenes que refuerzan la representación de movimientos vibratorios en la escena. Delante de la mirada fija del Sargento, figuras tenebrosas revolotean y bailan en la temblorosa luz de la luna. Lalita se le acerca; su silueta aparece por un momento y después desaparece en las borrosas sombras oscuras antes de reaparecer. Mientras le dice que Bonifacia está solita en su cabaña, la luz de una lámpara alumbra su rostro e ilumina su ondulante cabellera. Desde lejos, llenan el aire los rumores de la noche, uniéndose en un solo murmullo modulador de vida animal y vegetal.

El Sargento va a la cabaña y busca a Bonifacia por entre objetos sombríos, iluminados intermitentemente por la luz de su linterna y la luna. Contaminan el aire olores intensos, agrios, de comida putrefacta o de cadáveres en descomposición. La luz de la luna va por la habitación como si participara en la búsqueda y se detiene finalmente sobre Bonifacia, iluminando su escondrijo y mostrándola encogida, atemorizada: “La luna se había detenido sobre unas caderas inmóviles" (p. 174).

A partir de este momento de revelación, las descripciones de Bonifacia la representan repetidamente en una actitud inerte y rígida, parálisis comprensible por el miedo que le infunde el Sargento. La inocencia represiva de 
Bonifacia - expresada en parte por su estado inmóvil-desentona con el ambiente oscilante, altamente sensual, creado por los procedimientos descriptivos del autor. La violación inminente, en cambio, representa un acto perfectamente compatible con el contexto.

El despertar sexual de Bonifacia empieza como una experiencia brutal, pero es del todo consistente con el ambiente que reduce las relaciones humanas a un nivel de pasión e instinto básicos. Con una cuidadosa selección y acumulación de detalles significativos, el autor preludia el desenlace de la escena y construye un contex to tensamente estrucurado en el que este acto de violencia humana acaba siendo estilísticamente elocuente y verosímil.

Otros rasgos de la naturaleza también inducen procesos que llevan a la destrucción u ofuscación de distinciones entre planos de existencia. La realidad construida dentro de la novela encierra una visión sacada de varias dimensiones. La solidez de los objetos tiene su antítesis. Con una técnica impresionista, el autor da consistencia a un nivel de vaga indeterminación que acaba predominando en la novela. Descripciones e imágenes sobre el tema de la permeabilidad crean un mundo vaporoso donde la difusión y la insustancialidad penetran el cosmos entero.

El movimiento físico de los personajes es estorbado casi siempre por el estado flojo, esponjoso, de la tierra. Una imagen repetida les presenta hundiéndose en un pantano devastador de arena o lodo absorbente. La tierra misma carece de solidez y no les ofrece ningún asiento seguro, convirtiéndose en una masa líquida en la que los personajes representan ominosas simulaciones de gente semiahogada. El ambiente está espeso con vahos gaseosos. Nieblas, humos y brumas penetran e inficionan el aire, disolviendo continuamente la identidad de las formas. Tanto personas como objetos son tragados y absorbidos por el oleaje líquido de un mar amorfo, aéreo. En la descripción que sigue - la escena es Santa María de Nieva - los motivos de semianegación y disolución dan pie para la creación de ciertas metáforas claves que se entrelazan íntimamente con la acción de la escena:

Señaló hacia la Plaza y por allí venía el Teniente, medio cuerpo afuera de la mancha gaseosa, pestañeando bajo el sol, con camisa limpia. Cuando emergió de la bruma, tenía húmedas de vapor la mitad inferior del pantalón y las botas. -Venga conmigo, Sargento - ordenó desde la escalerilla-. Don Fabio quiere vernos...

El Teniente y el Sargento se hundieron en la bruma hasta la cintura. El embarcadero y las cabañas bajas del contorno ya habían sido devorados por las olas de vapor, que arremetía n ahora, altas y ondulantes, contra las techumbres y los barandales. En cambio, una luz diáfa na abarcaba las colinas, los locales de la Misión relumbraban intactos, y los árboles de troncos diluidos por la niebla, lucian sus copas limpias, y sus hojas, sus ramas y sus plateadas telarañas destellaban. (pp. 208-209) 
La densidad fluida del ambiente distorsiona la percepción de formas y movimientos: la descripción de actos normales crea a menudo impresiones de cuerpos sumergidos que flotan o nadan en un mar de nebulosas brumas. La selección de palabras añade muchas veces un rasgo adicional de deformidad al objeto percibido. Ambos aspectos pueden apreciarse en la distorsión visual impartida por estas líneas: "la bruma había crecido y, de lejos, los guardias parecían ahora mutilados, o cristianos vadeando un río de espuma"(p. 208).

La incertidumbre visual reduce a las personas y a los objetos al nivel más bajo de identidad; se convierten en siluetas unidimensionales o en sombras que presentan brevemente un perfil para esfumarse inmediatamente después en un fondo lóbrego.

En todas partes, en el desierto y en la selva, en la ciudad y en el yermo, el ambiente está preñado de olores fuertes y ofensivos de putrefacción. El calor y los procesos naturales disuelven constantemente las formas y la sustancia de la vida, devolviéndolo todo a un estado de masa indistinta. El hedor de la descomposición llega a ser más prominente y tal vez más sugestivo en términos temáticos en el último retrato de Fushía. Finalizado su viaje por el río, Fushía aparece por última vez en una colonia de leprosos donde la paulatina destrucción de la enfermedad le ha convertdio en criatura tan grotesca que ya no ofrece semejanza alguna a los seres humanos. Tullido, desdentado y putrefacto, Fushía vive completamente a merced de sus guardianes. Con los pies marca un registro de los días que pasan, enorgulleciéndose mucho en una actividad que es una patética caricatura de su autosuficiencia anterior. Periódicamente, y con una de sus comidas, Fushía tiene que sobornar a un oficial a que borre las rayitas de modo que pueda continuarse el registro. Al llegar a esta escena, no sólo se ha invertido el papel de Fushía de estafador sino que su lastimoso acto de soborno revela una escala de explotación que ha alcanzado increíbles proporciones. La enormidad de sus propios crímenes, sin embargo, parece eclipsada por la espantosa manera en que muere. La lepra destruye lentamente su identidad física y su capacidad mental hasta que resultan indistinguibles las sensaciones de vida y de muerte. Dice a Aquilino:

- Pero nosotros no sentimos ni con el sol ni cuando está nublado-grita Fushía-, nunca sentimos nada. Olemos lo mismo tod o el tiempo y ya no parece que apestara, sino que así fuera el olor de la vida. (p. 387)

La vida y la muerte de Fushía convergen y se funden en un vaho gaseosoun hedor punzante de descomposición. El le recuerda a Aquilino una flor selvática que conocían en la isla, una planta rara y misteriosa que se abría bajo los rayos del sol y emitía un líquido maloliente. A semejanza de esta flor, el ser de Fushía se le va rezumando en fétidas secreciones que, entremezcladas con el aire, se disuelven después en el ambiente. El lector recuerda, de la escena 
epilogal inmediatamente anterior, la descripción de la muerte simbólica de Jum y aquella frase tan curiosa encajada entre imágenes de fuerza disolvente solar: "Algo extraño transpira de él, así como está, quieto y aéreo... "(p. 382).

Para a mbos Jum y Fushía, y tanto en el nivel físico como en el simbólico, la muerte es una especie de efervescente disolución de estructuras físicas. Bajo la embestida violenta de un ambiente ajeno, la exterminación final llega mientras se escurre poco a poco la identidad individual, perdiéndose en los elementos fluidos y porosos de la naturaleza. La última descripción de Fushía lo representa como un montón de carne sangrienta que se va diluyendo en un ambiente líquido de alientos fuertes y vapores tibios, ondulantes, mientras cae la lluvia a cántaros.

Dentro de La casa verde, la imagen doble de entrampamiento y agresión por parte de la naturaleza crea una red compacta y bien construida de metáforas entrelazadas que enriquece con creces el contenido temático de la novela. Con repeticiones y con el efecto acumulativo de temas reiterativos, el uso del lenguaje figurativo de Vargas Llosa consigue una escala amplia y cada vez más dilatada de asociaciones. Debido a la manera hábil en que sabe utilizar la fuerza expresiva de las imágenes para dar aun más peso al sentido, las formas y los actos de la naturaleza adquieren un valor simbólico. Muchos elementos sin relación aparente entre sí se vuelven coherentes gracias a la capacidad unificadora del simbolismo metafórico. El mismo procedimiento da consistencia a la novela y realza el refinado tratamiento literario que sabe dar el autor a los problemas existenciales. La representación del escenario natural produce la visión sombría de una confrontación entre el hombre y las fuerzas hostiles que intentan destruir su existencia. 